\title{
A Case Study of Drama Education for Kindergarten Children in the United States: Drama Specialists' Beliefs and Practices
}

\author{
Su-Jeong Wee \\ Purdue University Calumet
}

\begin{abstract}
This case study examines two drama specialists' perspectives on the purpose of drama education and how their visions and beliefs are reflected in their drama practices during a sixweek kindergarten drama program. Two experienced drama specialists who have worked at public elementary schools located in the Midwestern United States were the main participants of this case study. Using a qualitative case study method, in-depth observations and semistructured interviews were carried out. Findings show that the drama specialists believed the purpose of drama education to be the building of self-confidence, creativity, awareness of the arts and respect for others. Both congruent and inconsistent relations between their beliefs and their teaching practices were observed. Based on these findings, an understanding of how specialists' beliefs and practices contribute to a broader understanding of drama education is further discussed.
\end{abstract}

Keywords : drama education, drama specialist, teacher’s belief, teacher's practice, kindergarten drama

Each school subject has its unique essential forms of cognition and discipline (Efland, 1990) and drama is no exception. The discipline of drama education consists of extensive specialized knowledge and holds its own ways of knowing. Classroom teachers usually teach drama to their students but not all teachers are trained in it. By examining beliefs and practices of drama specialists who are considered to have professional knowledge and rich field experience, classroom teachers can be informed of what should be considered important in drama education and how it should be taught in developmentally appropriate ways.

Corresponding Author: Su-Jeong Wee, Assistant Professor, Department of Behavioral Sciences, Purdue University Calumet, 2200 169th Street, Hammond, Indiana, 46323, USA. Email: sujeong.wee@purduecal.edu.
Although the terms "drama education" and "theatre education" have been commonly used interchangeably, there is a technical difference between the two. Drama education emphasizes participants' exploratory and meaning-making process, whereas theatre education highlights training for formal performance (Schonmann, 2000). Drama education is particularly important for young children because they learn about their world using their senses and motors/movements, which are the main tools of drama education (Osmond, 2007; Young, 2004). Drama can help introduce young children to the world around them and face the necessities of taking into account what others think, feel, and say because it involves working with others and acting out life issues (Mages, 2006; O’Neill, 1994; Richard, 1998). Drama activities provide 
children with opportunities to express their thoughts and feelings by using all of these senses and to develop their own perceptions about themselves and the world around them (Furman, 2002; Szecsi, 2008).

Many scholars have supported children's participation in school drama activities because drama provides an opportunity to facilitate children's social, emotional, linguistic, and intellectual development as well as to encourage creativity (Kelin, 2007; Mages, 2008). Specifically, drama is believed to have a positive impact on language development, oral and written fluency, critical thinking, literature comprehension, attitude toward English and Language arts, and literature appreciation (Barnes, Johnson, \& Neff, 2010; Chan, 2009; Dorion, 2009; Wagner, 1998). In spite of its important role in contributing to children's learning and development, drama is usually marginalized or absent from the curriculum, especially in the current school climate that emphasizes academic accountability (Bresler, 2002; O’Toole \& O’Mara, 2007). There is little time allotted in the daily routine for drama in early childhood settings due to the pressure that many teachers feel to cover too much material in too little time (Dean et al., 2007; Jones \& Reynolds, 1992). In such an educational climate, drama has often been conceptualized as a means to support learning other subject matter areas rather than as a foundation subject (Hatcher \& Petty, 2004; Mages, 2008; National Curriculum Council, 1990). Accordingly, in most cases, drama has been seen as a teaching method, which leads to missing its own discipline knowledge. Especially in such an educational environment, it is critical to examine how drama is taught to young children in an effort to find out where the focus of drama is placed on.

Schonmann (2000) classifies three interrelated orientations in the field of drama education: (a) the artistic-aesthetic, (b) the pedagogical-educational, and (c) the sociological-cultural, claiming that drama education in schools as a field for teaching and learning includes both the aesthetic and the utilitarian. First, regarding the artistic-aesthetic, drama is an art form that addresses the senses and awareness of the individual. Students learn to use drama language and achieve new modes of communication by participating in drama. The aesthetic functions of drama help students to understand the nature of drama as an art form and to make judgments which contribute to the understanding of the process and product. Next, the pedagogical-educational orientation is to teach drama in a practical way, helping students develop an identity with characters and situations. In a climate free from fear and shame, students must be allowed to develop their selfidentity, strengthen their self-image, build their self-confidence and share their emotions. Last, the sociological-cultural orientation in drama education addresses drama as a social art form, demanding the construction of meaning for both individuals and for society. Drama has been very close to the process of ritual and to the structure and motifs of critical events in the social and political arenas (O’Farrell, 1995). These three orientations in drama education are not separate but interrelated with each other in that drama education operates within an artistic medium and drama as pedagogy cannot be separated from drama as art. These orientations will be considered here in examining how drama is taught and practiced.

Another important issue to consider in drama education is that most American early childhood educators are not trained in drama education, which consists of specialized discipline-based knowledge (Wee, 2009). Limited financial resources, scarcity of state-mandated curriculum guides (Dean, Brown, \& Young, 2007), and teachers' concerns about the vast amount of preparation time needed (McMaster, 1998) are reported to hinder classroom teachers from incorporating drama in their curriculum. Drama specialists are assumed to have greater professional knowledge of drama than generalists and as a result of this knowledge they teach drama in a different way than generalists. Thus, examining the teaching methods and approaches of drama specialists can help early childhood educators understand specialized teaching practices of drama. 
Teachers view their classes, their students, and the world through personal lenses, making interpretations and devising actions to fit with their understanding of the world (Pratt, 1992; Wales, 2009). Educators should know what they teach, how they teach, and why they teach in order to achieve their goals. Teachers' beliefs about the purposes of education consist of their knowledge, thoughts, values, and images (Dean et al., 2007; Kempe, 2009; Rasmussen, 2010). Beliefs are assumed to act as filters through which one sees the world (Pajares, 1992). Teachers' beliefs influence their perceptions and judgments, which in turn, affect their behavior in the classroom (Ashton, 1990; Brookhart \& Freeman, 1992; Wilson \& Cooney, 2002). Beliefs influence the decisions that individuals make and also serve as the best indicators of their decisions (Goldin, Rosken, \& Torner, 2009; Pajares, 1992). Murphy and Mason (2006) also cite several sources in support of the assumption that "beliefs are the best indicators of the decisions individuals make throughout their lives” (p. 307).

Although much research has indicated that teachers' classroom practices are influenced by their beliefs, inconsistencies between the teachers' practice and their beliefs have been often documented (e.g., Fang, 1996; Galton \& Simon, 1980). For example, Galton and Simon (1980) indicate that the relationship between teachers' beliefs and their practices is not very strong. Inconsistent beliefs can be caused by the complexities of classroom life, which may constrain teachers from following their beliefs and providing instructions aligned with their theoretical beliefs (Fang, 1996). Teachers' beliefs could be situational and manifested in instructional practices only in relation to the complexities of the classroom (Mansour, 2009). This then raises the question of how important teachers' beliefs are for their practice and understanding of the socio-cultural context of teaching. In order to understand drama specialists' practices better, it is critical to explore their beliefs about the subject matter and the school culture where a drama program is implemented. It also helps to understand what choices they make and why these choices are made in the classroom. Thus, the purpose of this research lies in examining what beliefs drama specialists have about drama education for young children and how these beliefs are reflected in their teaching practices within a social culture.

\section{Methods}

This research was motivated by the researcher's desire to understand drama specialist's beliefs and practices as a former kindergarten teacher who taught drama as a generalist. In order to give guidelines to help generalists teach drama effectively to young children, two drama specialists' beliefs of purpose of drama education and their practices are described through qualitative case study in this article.

\section{Setting}

Lincoln School and Hamilton School were part of the Martin public school district located in a small University town in the Midwest (all names are pseudonyms). Martin was unusual in that it offered dance and drama programs. Both schools offered a six-week drama program every six months. After the six-week drama program, students proceeded to six weeks each of dance, music, and visual arts programs. Music and visual arts programs are provided every three months whereas drama programs are provided every six months.

During the course of this research, students attended a 30-minute drama class four times a week. Lincoln school had 353 students and 18 classrooms ranging from kindergarten to $5^{\text {th }}$ grade. Most students were from middle class families. The composition of ethnicity was $67 \%$ Caucasian, 15\% African-American, 14\% Hispanic, and 4\% Asian students (quoted from the school website). Hamilton had 345 students, also ranging from kindergarten to $5^{\text {th }}$ grade. The composition of ethnicity was $69 \%$ Caucasian, 20.6\% African-American, 4.1\% Hispanic, and $6.4 \%$ Asian students. The majority of the 
students were also from middle-class families.

The Martin School District's art curriculum categorized formal goals for fine arts under the headings of arts literacy, creation and performance, and historical/cultural connections. The curriculum guide stated that the arts are an embodiment of the human imagination, a record of human achievement, and a unique process of human beings. The study of fine arts, including dance, drama, music, and visual arts, promotes unique perceptions and perspectives as well as encourages students to understand the role of the arts in diverse cultures. In addition, it provides a solid foundation in the elements of each arts discipline. Arts education should balance creating, responding to, and knowing about the arts. The drama specialists who participated in this research planned and implemented their drama class activities based on this art curriculum guide.

In order to conduct research at these two schools, written permissions from the principals and the participating drama specialists were obtained. In addition, consent letters from all parents of students enrolled in the drama classes were acquired.

\section{Participants}

Two drama specialists, Rachel and Carrie (both are pseudonyms) were the participants of this study. Among a total of four drama specialists working in the Martin district, Rachel and Carrie were recommended as thoughtful and competent drama specialists by a former coordinator of the Martin district. When they were contacted and presented with the purpose of the research, both agreed to participate because they hoped other educators to understand the importance of drama education for young children through this research. Participants from different schools were chosen in order to gain understanding not only of different teaching practices but also of role of different school contexts.

Rachel, a drama teacher at Lincoln Elementary School, was a Caucasian in her midthirties. Rachel believed she had a great deal of experience in drama, including participation in plays at the community theatre during her high school days (interview with Rachel). She started as a dance major in college but changed to elementary education because she thought she would not make it as an actress in Hollywood. She went on to earn her masters' degree in elementary education. It was Rachel's twelfth year of teaching dance and drama in schools. She taught drama at Lincoln in the mornings, from 8:30 to 11:30 AM, having four classes a day with five-minute breaks between the classes.

Carrie, a drama teacher who had been working at Hamilton Elementary School for 11 years, was also a Caucasian in her mid-thirties. She described herself as an active and energetic person and a visual learner. Carrie said that she knew she wanted to be a drama and dance teacher at a young age. She expressed strong enjoyment in teaching and working with children. As a high school student, Carrie started teaching drama at a dance studio in town. Later, she earned her bachelor's degree in dance and physical education. She taught drama for one year before returning to the university to major in elementary education.

\section{Data Collection}

This research is a qualitative case study of drama education conducted in natural settings. The qualitative research method enables researchers to examine the complexity of interactions and the whole creative sequence involved in drama (Caroll, 1996; Hartfield, 1992; Yin, 1991). As naturalistic research, the approach to this study takes the perspective that "action can best be understood when it is observed in the setting in which it occurs" (Bodgan \& Biklen, 1998, p.5).

Rachel's kindergarten drama classes were observed at Lincoln Elementary School two to three times a week for three weeks, nine times in total in the fall of 2008. At Hamilton Elementary School, Carrie's kindergarten drama classes were observed two to three times a week for three weeks, 10 times in total. Each drama session lasted 30 minutes. At the beginning of 
the observation, in order to understand the structure and format of the class, incidental observation was carried out, focusing on the teachers' instructions and students' responses. As time went by and some of the patterns emerged, the specific issues relating to the research questions were more closely observed. During the observations, field notes were taken and transcribed. The researcher maintained herself as an observer without participating in any of the drama activities

Formal and informal interviews were conducted with both Rachel and Carrie to gain a better understanding of their teaching practices and their beliefs of drama education. Formal interviews in a semi-structured format with open-ended questions were carried out twice, for about 30 to 60 minutes, in each teacher's office or in the school cafeteria. The initial areas of interview questions included topics such as the teacher's educational background and teaching experiences, teaching philosophy, beliefs about drama education, expectations for the students' progress in their classes, and specific drama activities and practices (see Appendix). Informal interviews were conducted frequently, before or after their classes, as well as during their preparation time. All the interviews were audiotaped and transcribed.

In order to understand the school structure, system and mission, school pamphlets and brochures were also examined. The national, state and district drama and arts curriculum that Rachel and Carrie referred to was analyzed in order to understand their drama teaching in general. Each teacher's teaching plans, teaching materials, and evaluation forms were also analyzed in order to understand their specific approaches to drama teaching.

\section{Data Analysis}

Data collection and analysis procedures were based on the "interactive model" (Miles \& Huberman, 1984, p. 12), which refers to the activity of data collection and three types of analysis processes - data deduction, data display, and conclusion. The interactive model can provide continuous, iterative processes of analysis for better qualitative validity and credibility compared with a single, linear analysis process (Huberman \& Miles, 1994). While the inquiry was in progress, contact summary forms which consisted of main issues/themes, summary of information on each of the target questions, anything salient, interesting, or important, and new/remaining target questions (Stake, 2006) were filled out. These summary forms allowed the key points to be summarized and emerging themes to be recognized in order to guide planning for the next observation. In this process, data deduction was conducted by generating a conceptual level of coding system (Erickson, 2004), for example, creativity, confidence, and support for academic subjects. Data display and conclusions included follow-ups with the participants emphasizing their interpretations of the data collected, the triangulation of information, and the construction of meaning from the phenomena observed.

For investigator triangulation (Stake, 1995), multiple interim reports were made to identify and develop issues and audit what was known and to substantiate it with data collected. Belonging to a research group at a university, the researcher presented/shared each interim paper with other group members who worked, studied or were interested in early childhood education and/or arts education and received their feedback and suggestions during peer debriefings. These feedback and suggestions were selectively incorporated to enhance the trustworthiness of this research (Taylor \& Bodgan, 1998). Member checking was carried out by sharing interview transcriptions with the interviewees. The interviewees were asked to look through the transcripts and were invited to comment on and clarify any unclear points. If the interviewees wanted to add or change parts of the interview transcripts, they noted so on their copies. Revisions were made based upon these written comments and revised drafts were then shared with the interviewees to ensure that they had communicated what they intended to express. 


\section{Findings: Drama Specialists' Beliefs and Their Practices in Drama}

This section examines the drama specialists' beliefs of the purposes of drama education and how their beliefs were reflected in their classroom practices. Since each specialist held different beliefs, each one's beliefs and practices will be presented separately.

Rachel's Beliefs and Practice. When Rachel was asked what she believed to be important in drama education during the interview, she remarked:

I truly believe all children can learn differently. I really see as a dance and drama teacher that some students who are not so successful in the classroom because they are not good readers or have some academic problems do well in drama and dance class. It's a time for them not to have to worry about or not to write something, not to work for their potential. And some students who are very good academic students may not be quite good in dance and drama class. So it's a nice opportunity for the students to learn differently during the day. Every child deserves to be treated fairly in education by having teachers who are well qualified in their areas of teaching.

Rachel believed that "all children learn differently," or that there is a variety of learning styles. Felman and Solomon have developed a system for categorizing learning styles into four types: active and reflective, sensing and intuitive, visual and verbal, and sequential and global (as cited in Munro \& Rice-Munro, 2004). Rachel differentiated learning more broadly into two modes: the first being physically inactive, such as reading, math, or writing, and the other as being physically active, such as drama and dance. For Rachel, students who like to move their bodies preferred drama because it was more physically active than other school subject matter. Rachel's belief that all children learn differently related to her belief in the uniqueness of each child. She supported the notion that children have diverse strengths and differing abilities in different areas.

Second, Rachel believed in the uniqueness of drama education. For her, drama class provided the opportunity for children to experience a unique subject matter taught in a distinct way. In drama class, students moved their bodies and expressed emotions, unlike the traditional academic mode of learning. Rachel's comments indicated that she believed that drama class provided a time for students to feel more relaxed and comfortable than in other academic subjects that caused greater "pressure." A student who did well in academic subjects might not be as good at drama and conversely, a student who may not be academically inclined might be excellent at drama. Rachel saw drama class as a place where students felt less anxiety than in academic subject matter classes. These comments show that Rachel's drama class existed within a larger context in which academic performance was emphasized and the arts were marginalized. School culture and ways of practice, in general, greatly influence school arts to accomplish expressive and intellectual goals (Bresler, 2002).

Finally, Rachel believed that all children should be provided drama instruction at school and that they should work with teachers who have specialized knowledge of the discipline. It is very important for classroom teachers to have training and experience in creative dramatics (Sextou, 2002), yet many teachers have little or no training in drama (Flynn, 1997; Wee, 2009). Although Rachel emphasized a teacher's special training and qualifications, she never received a formal education or training in drama. As introduced in the Method section, she had brief theater acting experience as a high school student and dance had been her major in college for two years before switching to education. Rachel placed greater importance on teaching techniques than on knowledge content, suggesting that for her, pedagogy was of even greater importance than specialized knowledge of the discipline or that specialized knowledge alone was not enough to qualify someone to teach drama. 
When asked what important experiences students should have in her drama class, Rachel stated:

I guess students should feel comfortable and safe to try new things in front of group of people. It's important to be comfortable enough to work together with other students. I try to do quite a lot of group work in the activities. They have to practice being in front of [a] group of people, be asked to improvise something while people are watching them. That can help so many situations in their lives, like any kind of class work or job interview. So many different situations in their lives require confidence and drama can help their confidence. Also, drama helps children to use their creativity. Drama class is different from the regular class where lots of times they are asked to read not just material and answer certain questions but to be able to use their mind a little bit. You have to practice being creative, too. It can be developed.

Rachel commented about what she sees as two key experiences of drama education: to develop self-confidence and to develop creativity. Rachel defined confidence as feeling comfortable and safe to try new things in front of groups of people. Although she used the term "confidence" when explaining children trying out new things in front of others, what she actually meant was self-confidence, which means to be self-assured in one's personal judgment, ability and power. She believed that self-confidence is important both in school and in life outside and beyond the school. In addition, Rachel believed that drama education was worthwhile because it developed creativity. According to Rachel, creativity is something that can be developed through educational experiences. Creativity has been defined in as many ways as there are scholars in the field. Some generally agreed upon notions of creativity include (a) fluency, the ability to produce many ideas; (b) flexibility, the ability to produce different categories of ideas; (c) originality, the ability to produce new or different combinations of ideas; and (d) elaboration, the ability to embellish ideas so that they become more provocative and evocative. Rachel emphasized originality most strongly among these four elements and her teaching practices also revealed her emphasis in this area. For example, when students performed, Rachel encouraged them to demonstrate new ideas rather than producing as many different ideas as they could or increasing complexity or elaborating upon a single idea. The following vignette illustrates such an activity implemented in Rachel's kindergarten drama class.

November 13: "I want to see a different one.". The kindergartners are pantomiming animals. Children sit on the floor facing Rachel. First, Rachel demonstrates how to pretend to be a cat, and then calls the names of each child one at a time, giving each the opportunity to act alone on the stage. The first girl pretends to be a tiger. She gets down on all fours and strolls around the stage area. As she approaches other students, roaring like a tiger, the audience makes frightened facial expressions and shrinks back. The next few children take their turns on stage; they move and roar like the first girl. Rachel asks the children what animal they are portraying, and they each respond "tiger."

Rachel: Let's choose a different animal when it is your turn. Okay?

Several more children take the stage and become tiger-like. When they are asked to name the animal they pretended, they respond that they were a cheetah, a lion, or a panther.

Rachel: Some people really like being a tiger. But let's try to be something different from a tiger or a cheetah. I really want to see a different one.

Still, more wild cats take the stage.

In this classroom activity, when children mimicked or carried out similar representations, Rachel encouraged the children to come up with 
something different. Despite her repeated reminders to show something new, the students continued to show imitative behavior. The lack of creative ideas and expressions could have been caused by students having difficulties in coming up with new ideas. In such a situation, rather than merely repeating a request to the children to show new ideas, it would be more effective for the teacher to guide children to think in a different way, even within the same animal, and to help children elaborate their ideas and expressions by reflecting on the animals' facial expressions, characteristics and movements. Young children need guidance and detailed explanations for elaborated or fluent expressions. When asked about how she encourages students to produce creative movements, Rachel answered:

I think that's actually a part of the developmental process of creativity. Students are uncomfortable with it at first. Beginning stages of development include imitating and following. For example, we are going to try to do animals today. So, students who are shy about it might just imitate animals other students do. First, that's okay. After a while we may have a rule that if somebody else has done a dog, you can't do that. You have to do something else. It's a very simple example, but just helping them to move from imitating to something new. For some students it comes very naturally and [it is] easy [for them] to come up with different ideas, but other students need a little bit more prompting. If some students didn't know what to do, I might whisper the idea in their ear, saying, "I will give you an idea." I really do see a difference. Some very shy and reserved students in the kindergarten, by the time they get to $3^{\text {rd }}$ grade, are much more comfortable using creativity, more brave in front of the group. They just needed more practice.

Rachel related creativity to self-confidence in that students cannot express something original until they gain confidence through performing in front of others, even if their performances are imitative. Rachel believed creativity to come with time; that is, over time, as students became comfortable in performance situations, they would become more creative. One of the teaching strategies that Rachel used to help students build self-confidence was to have five rules to follow, one of which included "Everybody participates," meaning every student has to take a part in any of the activities during her drama instructions. Refusal was not an option. Rachel explained during the interview that she felt that some students' refusal to participate was caused by a lack of confidence and that the participation rule helped children to build self-confidence through repeated practice of performance and improvisation in front of a group. Moreover, Rachel thought that as children felt more comfortable working within a group without being the focus of audience attention, their overall self-confidence increased. Accordingly, as a first step, Rachel stated that she allowed the children to show whatever they could or wanted to do. She then gave specific directions after which the children worked with a group. Based on actual observations during this research, children engaged in more active movements when they acted together than when each acted alone on the stage. When Rachel determined that they had enough imitative experience, she encouraged children to try unique expressions.

However, this notion that self-confidence enables creativity was not always consistently apparent in practice. For example, four months after the start of the drama session, many students continued to imitate despite Rachel's encouragement that they present their own unique ideas. Rachel's specific instructions of how to move or her demonstration prior to students acting out might have limited opportunities for students to develop their own individual expression. Developing selfconfidence should not be limited by mandatory participation or practicing within a group. It is important to note that there can be other reasons for students' hesitance in participation, including personal characteristics (e.g., extrovert or 
introvert), physical shortcomings, lack of interest in drama, or disinclination for movement, in addition to the lack of selfconfidence. Thus, it is also very crucial to consider ways in which the class atmosphere may encourage risk-taking. This would suggest that open tasks that present divergent possibilities, rather than one correct way of doing things, might be an important part of drama class. Rosenberg (1987) supports the belief that the psychological climate is very important for students in creative drama, suggesting that teachers should emphasize the importance of freedom. This freedom includes freedom to fail, to learn, and to enjoy success. The environment must be comfortable, but still maintain a sense of purpose. Rachel's class could be described as structured with mostly teacher-focused activities and repeated reminders of the five expectations, including "Follow[ing] directions" and "Keep[ing] hands and feet to yourself." Rachel's classroom atmosphere may work well in terms of classroom management, but on the other hand, it may prohibit children's creative expressions by emphasizing the importance of following the teacher's directions. Rachel believed drama education worthwhile because it fostered personal growth, which is the pedagogicaleducational orientation of drama education (Schonmann, 2000). By creating a safe and secure environment, drama helps students develop an identity with characters and situations and leads to personal growth, including self-confidence.

Carrie's Beliefs and Practice. Carrie's view of drama, both in how she talked about her valuing of drama education and her actual classroom practice can be summarized as a heightened awareness of drama and respect for others and different cultures. When she was asked about what she emphasized in her drama class for students to learn, she remarked:

I emphasize awareness of the arts to the students while teaching. Many students may be exposed to the fine arts because we always take those things out. I usually do not emphasize performances or technical things but emphasize enjoying those things around them, including music, dance and drama. Also, respecting other people's works and respecting other cultures is another thing emphasized in my class. In drama, we talked about the stories and talked about stories from cultures all over. It's such a big topic! For example, the $5^{\text {th }}$ graders did some activities about the Native American culture last year. What they did with the classroom teacher was writing their own poems and we acted out the poems they wrote in drama class. With the art teacher, they made really cool masks. We tried to put them into a kind of performance. I think children are [both] aware and not aware of art, because we do it every day, so students are not constantly thinking about it. I want my students to experience arts in their environment, but I cannot do enough because the class time is too short!

Carrie emphasized awareness of the arts and respecting others and other cultures. First, Carrie considered drama as art and tried to make connections between drama and other art forms although school drama, in general, has been regarded as subservient - a means to support learning in other areas. In her teaching practices, while explaining musical theatre, she classified actors, scenery, choreography, and music as art components and asked students what it looked like when all these components came together. Typically, prior to a main activity, Carrie introduced and explained various drama concepts and components in detail, such as genres of drama (e.g., tragedy, comedy) and elements of drama (e.g., character, script, setting, makeup, stage, lighting). After explaining these concepts, Carrie sometimes practiced them with the children. The vignette below illustrates the first graders' drama session, practicing images in still-shot pictures.

November 12: Frozen Pictures. Carrie introduces two kinds of photographs: a still shot and an active shot. First, she goes into 
greater depth in her explanation of a still shot.

Carrie: While you are sitting, we sometimes figure out what's going on. Sometimes the way you are sitting or thinking, we can tell certain things about you. There are still, or frozen, pictures. Frozen and still pictures may be like a photographer's painting.

Carrie shows a large black-and-white photograph to the students and asks what the picture can tell them. Carrie and the children look at the picture for a while. As no one replies to her earlier question, Carrie asks some more questions.

Carrie: "What kind of information can you figure out or tell just looking at this picture? In drama, we call it a still picture or frozen picture. It's not going to change. In a frozen picture, what kind of things can you learn looking at those things?”

Several children raise their hands and Carrie calls students' names one by one. Children answer, "We can probably tell what action," "The environment making the room around the people," "How we are feeling" and "Background. What else is going on." Carrie nods her head and shows another picture. It is a black and white stillshot portraying six children solving math problems written on the board.

Carrie: "What are the children in the picture doing?"

A student says they look bored. As Carrie asks why he thinks that, the student replies that the boy in the image looks bored because he doesn't like math. Other student answers, “They're doing math problems and thinking how they solve them." Carrie continues to ask students what facial expression they would make when they solve math problems. Each student makes a different face, ranging from frowning to serious. After listening to the children's ideas on the picture, she puts it on the board and says, "We can tell many things from frozen and still pictures." After looking at one more picture, Carrie leads the children in a still shot activity during which children freeze, pausing and holding still as if they are in a still shot.

The main purpose of this activity was to acquire knowledge of a still shot. One of the fundamental aspects in experiencing drama as an art form is to experience sensitivity to sensory properties, which can lead to artistic and aesthetic perception. The artist deliberately creates an aesthetic image by giving dramatic structure to color, shape, texture, sound, or gesture, depending on the medium of his or her art. In drama, visual, auditory, olfactory, gustatory, tactile, and kinesthetic images can be created (Broudy, 1972). In the vignette above, the children were asked to look at the pictures carefully by being guided to draw their attention to sensory properties such as color or shape in the pictures. The children expressed their ideas about the pictures and their ideas were expanded further through reflecting processes. Through this activity Carrie not only introduced and defined a still shot but also cultivated children's sensory perception. Since children vary in how well developed their senses are and in the types of images and experiences they have stored (Rosenberg, 1987), it is particularly necessary for teachers to guide children to foster development in their ability to perceive sensory properties.

For Carrie, one of the most basic things that students learn in drama class was what drama is and in a larger sense, what art is. Carrie pointed out that the fact that not all students received drama instruction reflected the trend of emphasizing academic subjects to the neglect of the arts. She did not take a performance approach, one that is often typical of early childhood art instruction, believing that her students enjoyed drama because she did not stress performance and techniques and there was more freedom than in other classes. In drama, students have the opportunity to express themselves and use their imagination without the fear of being wrong. This is what Carrie viewed as one of the purposes of drama education: to appreciate and enjoy drama as an 
art form.

In addition to awareness of the arts, Carrie believed that respect for others and other cultures should be cultivated through drama education. She believed that all students' efforts to perform in front of the group, whether considered successful or not, should be respected. In class, Carrie praised students in order to reinforce positive responses to all performances. Occasionally, she added feedback such as "Next time you will be better if you have more energy," or "You will be better if your voice is louder" for improvement. However, although Carrie believed that students would improve after gaining experience and receiving positive feedback or constructive suggestions, she felt it difficult to give comments on all thirteen to fifteen of her students' performances in such a short time. Most of the time, Carrie clapped after every performance without comment. Instead, Carrie tried to provide a chance for the children to learn respect for others through developing an awareness of self and an awareness of self within the group. According to her, students develop self-awareness through individual work: exploring body, movement, and voice. Little by little, she encouraged students to be aware of themselves in relation to others in the group, interacting with others and seeing themselves as part of a greater whole. Based on this belief, Carrie planned a balance of individual, small group, and large group activities. A sense of group begins to emerge through discussing, sharing, and working together in drama class (Rosenberg, 1987). As the group grows closer, individuals begin to share ideas and images and to listen to one another. Even when there are many similarities among groups, differences still exist.

Carrie believed that students can develop respect for others and other cultures by learning stories from other countries. She recalled a teaching experience in which she introduced a Greek play to the students. As a result, she found that students gained an understanding of Greek customs revealed in the play and some ingrained cultural philosophies inherent to the story. In addition to storybooks, she also presented videos and showed pictures to help students understand foreign cultures. She also cited the integrated study on Native Americans and commented that the students really enjoyed it. Carrie believed that students gained understanding and respect for other cultures through these kinds of experiences. Acquiring knowledge of a culture is commonly equated with respect for the culture (Day, 1998). Thus, Carrie's belief assumes that getting to know a new culture leads to appreciating and respecting it. The acquisition of cultural knowledge should serve as a significant foundation for intercultural encounters based on respect. Reliance on cultural knowledge can provide insight into cultural differences that one can apply in order to respectfully interact with people from other cultures. Carrie's view relates to Pepper's (1967) assertion that art reflects important cultural values. Drama is a way for students to understand factual information within a larger cultural context (Goldberg, 2001; Wagner, 1998). Through drama, students learn explicit and implicit cultural behaviors and customs. Carrie added during an interview that she sincerely wanted to reflect the various cultures of her students into drama activities but that it was very difficult to do so mainly due to the lack of time. Her kindergarten drama instructions were mostly composed of storytelling, pantomime, and improvisation. Rather than having a separate special cultural theme or activities related to a certain culture, incorporation of cultural elements into daily drama activities is more developmentally appropriate for young children and can prevent the pitfalls of "tourist curriculum," which may reinforce stereotypes and leads to a superficial understanding of a culture (Derman-Sparks \& Edwards, 2010).

\section{Conclusion}

This case study has shown examples of what drama specialists in the United States believe to be the purpose of drama education for children and how their practices reflect these beliefs. Their beliefs reflected important values about 
what drama education should be and why it is worthwhile. A teacher's knowledge of his or her profession is situated in three important ways: how it is related to specific groups of students, how it is related to particular academic material to be taught, and whether it is embedded within the teacher's unique belief system (Kagan, 1992). Both drama specialists in this study saw drama as unique from teaching and learning other academic subject areas and they both held the view that drama education should value children's personal and social development. Furthermore, they saw drama as a subject matter with its own set of disciplinary contents and skills. At the same time, they differed a great deal in what they emphasized. Rachel considered drama education to be worthwhile because it developed self-confidence and creativity as well as accommodated students' different learning styles, which lie in the pedagogical-educational orientation of drama education. Carrie saw developing awareness of arts and respect for others and other cultures as most important, which falls in the artisticaesthetic as well as the sociological-cultural orientations. Based on Calderhead's (1996) teachers' beliefs, both drama specialists viewed teaching as a process of guiding children's learning or a process of developing social relationships, rather than viewing teaching as a process of knowledge transmission.

Although teachers may have similar content knowledge, they are likely to teach in different ways because teachers' beliefs are more powerful than their knowledge in influencing the way in which they teach (Nespor, 1987). Teacher's beliefs about subject matter have been found to influence day-to-day decisions about what to teach, what to skip, and how much class time to devote to a particular topic (Cronin, 1991; Pajares, 1992). Complexities of classroom life may constrain teachers' abilities to follow their beliefs and provide instruction that is aligned with their theoretical beliefs. Thus, the teachers' beliefs and views were anticipated to shape their practice in the classroom and some connections were found in their teaching practices in this research. For example, Rachel gave children more opportunities to express individual ideas and emotions than Carrie did. This was consistent with Rachel's belief that performing built self-confidence. On the other hand, Carrie balanced individual, small group, and large group activities, providing children with opportunities to work with others in order to develop respect for each other. She provided opportunities for individual performance because she believed knowing one's self preceded knowing and respecting others. This reflected her belief that both self-awareness and awareness of self within a group were important in terms of developing respect for others.

In Carrie's case, in order to facilitate learning respect for and gaining greater understanding of cultures, she introduced stories, videos, and pictures. Imparting information and providing visual aid alone may not develop or change children's attitudes or feelings. This was something that could not be found in Rachel's class where cultural issues were not directly addressed as a part of drama instruction. On one occasion, there was an activity where students were to attempt to make the audience laugh by words or movements. A boy took the stage and asked, "Do you know how Chinese people speak?" No one replied, and he went on to stretch his eyes up using his fingers and say, "Gonichiwa," a Japanese word meaning "good morning." Rachel stopped his presentation, saying it was offensive. Several days later, she told me that she warned the boy not to do things that insult other ethnicities and give incorrect stereotypical images. She said the boy did not intentionally mean to disrespect Japanese or Chinese cultures, but did it for fun. Respectful representation of one's culture becomes an important basis for respecting cultural differences (Jaeger, 1995). This illustrated one of the instances of difference between the two specialists' attitudes about drama as cultural awareness, and how this difference played out in the classroom.

Although there were examples of what the teachers believed to be important purposes of drama education as practiced in the classroom and summarized above, inconsistencies also 
existed. For example, Rachel's value of creativity as originality was reflected in her encouragement of students to develop unique ideas. Yet, despite this value, she taught in a teacher-centered way that encouraged uniform movements, mimicking her demonstrations in her drama classes. According to Torner (2002), inconsistent beliefs can be held simultaneously without becoming evident because they are connected to different contexts and consciousness. In this research, such discrepancies between beliefs and practices were identified to be caused by teachers' lack of discipline knowledge at an individual level and by characteristics of school drama situated at a socio-cultural level.

Both drama specialists participating in this research had formal education only in dance, not in drama, and they have taught both dance and drama at schools, which is not common in the United States. Specialists usually only teach one subject in which they have specialized. However, as dance and drama have some traits in common, such as using kinesthetic images, dance can be applicable to drama in certain ways. However, considering that drama is a unique subject, teaching it certainly requires its own knowledge, qualities and formal training. Drama specialists are assumed to be knowledgeable of qualities of the arts, sophisticated techniques, creativity and excellence. Rachel reported that when she started teaching drama without knowledge of drama, she had many difficulties. However, after several years of practice, she gained the techniques and skills and had come to feel comfortable. Carrie also said she was more comfortable while teaching dance than teaching drama because she knew dance better. Developmentally appropriate drama experiences will not be guaranteed by drama specialists alone because most drama specialists have not been trained to work with young children. On the other hand, early childhood classroom teachers have few resources to provide quality drama experiences to their students (Brown \& Pleydell, 1999; Kempe, 2009). By bringing different knowledge and experiences into the classroom, collaboration between a drama specialist and a classroom teacher can be a valuable approach to expanding and complementing teachers' specialties (e.g., DeMoss \& Morris, 2002; McCammon \& Betts, 1995). With respect specifically to drama, collaboration can provide a strong foundation in drama skills and techniques such that drama becomes an integral part of the teacher's repertoire (Yaffe, 1989). Lack of professional knowledge of the field might cause drama specialists to focus on techniques or skills rather than core knowledge of drama, including history of the theatre, aesthetic and philosophical inquiry, and theatre criticism.

Most of the research indicates that educational beliefs in general and teachers' beliefs in particular are not context-free (Fang, 1996; Pajares, 1992). Thus, school culture may strongly influence discrepancies between beliefs and practices. Drama instructions observed in this research were found to be characterized by teacher-centered instructional strategies that limited child-initiated exploration. The views of the purposes of drama education had little to do with understanding the art. During the interviews, the specialists frequently pointed out a lack of time to fulfill their desires and visions in drama practices. Due to the short time allotted to drama lessons - thirty minutes - the specialists usually provided a time limit on how long students practiced or acted out certain activities. Drama consisted of short performance units, such as practice of facial expression, a couple of short pantomimes, and improvisation. Each short unit hurriedly changed its turn and did not have enough time to carefully reflect and think about their ideas. As soon as the teacher gave instructions, bustling students began moving their bodies without a moment to think. Students in the drama classes had little opportunity to express their own feelings. The teachers skipped giving feedback or comments on individual students' performances. This phenomenon reflects the unfortunate failure to regard drama as its own distinct art discipline in current school culture. School drama should provide contexts not only for technical skill acquisition but also for individual experimentation with materials, ideas, or devices 
to convey expressiveness (Bresler, 1998; Hamblen, 2002).

Drama is usually marginalized or absent from the curriculum (O'Toole \& O'Mara, 2007) in the current school climate that emphasizes academic accountability. Drama learning experiences for children are among the most highly praised but least practiced of learning experiences in schools (Dillon, 1988). Considering the current school climate which greatly emphasizes academic accountability, it is strongly recommended that drama specialists work with classroom teachers for collaborative teaching in order to address diverse needs in the classroom and to integrate drama with core subjects. Such collaborative efforts will provide high-quality drama education and improve students' academic achievements. Consequently, teachers' desires to meet complicated organizational demands and diverse students' needs and interests can be easily overlooked (Hargreaves \& Fullan, 1992).

Appendix: Interview protocol

1. What do you emphasize in your teaching drama?

2. What do you believe is the purpose of drama for young children?

3. What do you want your students to learn in your drama class?

4. What strategies do you use in order to encourage the children's drama activity?

5. Why is drama important to young children?

6. Any other comments?

\section{References}

Ashton, J. R. (1990). Editorial. Journal of Teacher Education, 44(1), 2.

Barnes, M., Johnson, E., \& Neff, L. (2010). Learning through process drama in the first grade. Social Studies and the Young Learner, 22(4), 19-24.

Bodgan, R. C., \& Biklen, S. K. (1998). Qualitative research for education: An introduction to theory and methods. New
York: Allyn and Bacon.

Bresler, L. (1998). "Child art," "Fine art," and "Art for children": The shaping of school practice and implications for change. Art Education Policy Review, 100 (1), 3-10.

Bresler, L. (2002). School art as a hybrid genre. Children's contextual art knowledge. In L. Bresler, \& C. Thompson (Eds.), The arts in children's lives: Context, culture, and curriculum. Norwell, MA: Kluwer Academic Publishers.

Brookhart, S. M., \& Freeman, D. J. (1992). Characteristics of entering teacher candidates. Review of Educational Research, 62, 37-60.

Broudy, H. (1972). Enlightened cherishing: An essay on aesthetic education. Urbana: University of Illinois Press.

Brown, V., \& Pleydell, S. (1999). The dramatic difference. Portsmouth, NH: Heinemann.

Caroll, J. (1996). Critical and transformative research in drama classrooms. In P. Taylor (Ed.), Researching drama and arts education: Paradigms and possibilities (pp.72-84). London: Falmer Press.

Calderhead, J. (1996). Teachers: Beliefs and knowledge. In D. Berlioner \& R. Calfee (Eds.), Handbook of educational psychology (pp.708-725). New York: MacMillan.

Chan, Y. (2009). In their own words: How do students related drama pedagogy to their learning in curriculum subjects? Research in Drama Education, 14(2), 191-209.

Cronin, J. (1991). Science teacher beliefs and their influence on curriculum implementation: Two case studies. Journal of Research in Science Teaching, 28(3), 235-250.

Day, K. D. (1998). Fostering respect for other cultures in teaching intercultural communication. In K. S. Sitaram \& M. H. Prosser (Eds.), Civic discourse: Multiculturalism, cultural diversity and global communication (pp.131-142). Stamford, CT: Ablex pub.

Dean, J., Brown, R., \& Young, S. (2007). The possum story: Reflections of an early childhood drama teacher. Australian Journal of Early Childhood, 32(4), 1-6.

DeMoss, K., \& Morris, T. (2002). How arts integration supports student learning. 
Retrieved September 12, 2005, from http://www.capeweb.org/demoss.pdf

Derman-Sparks, L., \& Edwards, J. (2010). Antibias education for young children and ourselves. Washington D. C.: National Association for the Education of Young Children.

Dillon, D. (1998). Letter to the readers. Language Arts, 65, 7-9.

Dorion, K. (2009). Science through drama: A multiple case exploration of the characteristics of drama activities used in secondary science lessons. International Journal of Science Education, 31(6), 2247-2270.

Efland, A. (1990). A history of art education: Intellectual and social currents in teaching the visual arts. New York: Teachers College Press.

Erickson, F. (2004). Demystifying data construction and analysis. Anthropology and Education Quarterly, 35, 486-493.

Fang, Z. (1996). A review of research on teacher beliefs and practice. Educational Research, 38(1), 47-64.

Flynn, R. (1997). Developing and using curriculum-based creative drama in fifth reading/language instructions: A drama specialist and a classroom teacher collaborate. Youth Theatre Journal, 11, 47-69.

Furman, L. (2002). In support of drama in early childhood education, again. Early Childhood Education Journal, 27(3), 173-178.

Galton, M., \& Simon, B. (1980). Progress and performance in the primary classroom. London: Routledge and Kegan Paul.

Goldberg, M. (2001). Arts and learning: An integrated approach to teaching and learning in multicultural and multilingual settings (2nd ed.). New York: Longman.

Goldin, G., Rosken, B. M., \& Torner, G. (2009). Beliefs - No longer a hidden variable in mathematical teaching and learning processes. In J. Masses \& W. Schlogmann (Eds.), Beliefs and attitudes in mathematics education (pp. 1-18). Rotterdam, The Netherlands: Sense Publishers.

Hamblen, K. (2002). Children's contextual art knowledge. In L. Bresler, \& C. Thompson
(Eds.), The arts in children's lives: Context, culture, and curriculum. Norwell, MA: Kluwer Academic Publisher.

Hargreaves, A., \& Fullan, M. (Eds.), (1992). Understanding teacher development. New York: Teachers College Press.

Hartfield, G. (1992). Workbook of sociology. Stuttgart: Kroener.

Hatcher, B., \& Petty, K. (2004). Visible thought in dramatic play. Young Children, 59(6), 7982.

Huberman, A. M., \&Miles, M. B. (1994). Handbook of qualitative research. Thousand Oaks: Sage.

Jaeger, K. (1995). Teaching culture- state of the art. In A. A. Jense, K. Jaeger, \& A. Lorensten (Eds.), Intercultural competence: A new challenge for language teachers and trainers in Europe (pp.31-52). Denmark: Center for Language and Intercultural Studies.

Jones, E., \& Reynolds, G. (1992). The play's the thing. Teachers' role in children's play. New York: Teachers College Press.

Kagan, D. (1992). Implications of research on teacher belief. Educational Psychologist, 27(1), 65-90.

Kelin, D. (2007). The perspective from within: Drama and children's literature. Early Childhood Education Journal, 35(3), 277-284.

Kempe, A. (2009). Resilience or resistance? The value of subject knowledge for drama teachers. Research in Drama Education, 14(3), 411-428.

Mages, W. (2008). Does creative drama promote language development in early childhood? A review of the methods and measures employed in the empirical literature. Review of Educational Research, 78(1), 124152.

Mages, W. (2006). Drama and imagination: A cognitive theory of drama's effect on narrative comprehension and narrative production. Research in Drama Education, 11(3), 329-340.

McCammon, L., \& Betts, J. D. (1995). Helping kids to "imaginate": The story of drama education at one elementary school. Unpublished Manuscript. (ERIC document 
ED 430262).

McMaster, J. (1998). Doing literature: Using drama to build literacy. The Reading Teacher, 51(7), 574-584.

Miles, M. B., \& Huberman, A. (1984). Qualitative data analysis. Beverly Hills, CA: Sage.

Monsour, N. (2009). Science teachers' beliefs and practices: Issues, implications and research agenda. International Journal of Environmental \& Science Education, 4(1), 25-48.

Munro, R. A., \& Rice-Munro, E. J. (2004). Learning styles, teaching approaches, and technology. Journal of Quality and Participation, 27(1), 26-32.

Murphy, P. K., \& Mason, L. (2006). Changing knowledge and beliefs. In P. A. Alexander, \& P. H. Winne (Eds.), Handbook of educational psychology (pp.305-324). Mahwah, NJ: Erlbaum.

National Curriculum Council (1990). English non-statutory guidance. York: National Curriculum Council.

Nespor, J. (1987). The role of beliefs in the practice of teaching. Journal of Curriculum Studies, 19, 317-328.

O'Farrell, L. (1994). Education and the art of drama. Geelong, Australia: Deakin University Press.

O’Neill, C. (1994). Here comes everybody: Aspects of role in process drama. Drama in Education Journal, 18(2), 39-52.

Osmond, C. (2007). Drama education and the body: "I am, therefore I think." In L. Bresler (Ed.), International handbook of research in arts education (pp.1109-1118). Dordrecht, The Netherlands: Springer.

O’Toole, J., \& O’Mara, J. (2007). Proteus, the giant at the door: Drama and theatre in the curriculum. In L. Bresler (Ed.), International handbook of research in arts education (pp. 203-218). Dordrecht, Netherlands: Springer.

Pajares, M. F. (1992). Teachers' beliefs and educational research: Cleaning up a messy construct. Review of Educational Research, 62(3), 307-332.

Pepper, S. C. (1967). Concept and quality. La
Salle, IL: Open Publishing Company.

Pratt, D. (1992). Conception of teaching. Adult Education Quarterly, 42(4), 203-220.

Rasmussen, B. (2010). The "good enough" drama: Reinterpreting constructivist aesthetics and epistemology in drama education. Research in Drama Education, 15(4), 529546.

Richard, A. (1998). Different solutions to the same problems. Children and families, 17(3), 10-16.

Rosenberg, H. (1987). Creative drama and imagination: Transforming ideas into action. Holt Rinehart Winston.

Schonmann, S. (2000). Theatre and drama education: Themes and questions. In B. Moon, S. Brown, \& M. Ben-Petez (Eds.), Routledge international companion to education (pp. 944-955). London: Routledge.

Sextou, P. (2002). Drama teacher training in Greece: A survey attitudes of teachers towards drama teachers. Journal of Education for Teaching, 28(2), 123-133.

Stake, R. (2006). Multiple case study analysis. New York: The Guilford Press.

Stake, R. (1995). The art of case study research. Thousand Oaks, CA: Sage.

Szecsi, T. (2008). Creative drama in preschool curriculum: Teaching strategies implemented in Hungary. Childhood Education, 85(2), 120.

Taylor, S., \& Bodgan, R. (1998). Introducing to qualitative research methods ( $3^{\text {rd }}$ ed.). New York: John Wiley.

Torner, G. (2002). Mathematical beliefs - A search for common ground: Some theoretical considerations on structuring beliefs, some research questions, and some phenomenological observations. In G. C. Leder, E. Pehkon, \& G. Toner (Eds.), Beliefs: A hidden variable in mathematics education (pp.73-94). Doordrecht, The Netherlands: Kluwer.

Wagner, B.J. (1998). Educational drama and language arts: What research shows. Portsmouth, NH: Heinemann.

Wales, P. (2009). Positioning the drama teacher: Exploring the power of identity in teaching practices. Research in Drama Education, 14(2), 261-278. 
Wee, S. J. (2009). A case study of drama education in early childhood. Journal of Research in Childhood Education, 23(4), 489-501.

Wilson, M., \& Cooney, T. (2002). Mathematics teacher change and development. In G. C. Leder, \& E. Pehkonen (Eds.), Beliefs: A hidden variable in mathematics education (pp. 127-148). Doordrecht, The Netherlands: Kluwer.

Yaffe, S. H. (1989). Drama as a teaching tool. Educational Leadership, 46, 29-32.
Yin, R. K. (1991). Case study research design and methods. Newbury Park, CA: Sage.

Young, S. (2004). "It's a bit like flying”: Developing participatory theatre with the under-twos - A case study of oily cart. Research in Drama Education, 9(1), 13-28.

Received April 7, 2011

Revision Received May 29, 2011

Accepted July 5, 2011 